\title{
ESCRITOS E OLHARES PLURAIS, VALORES ÉTICOS, POLÍTICOS E ESTÉTICOS NA EDUCAÇÃO DA INFÂNCIA
}

\author{
PLURAL WRITING AND VIEWS, ETHICAL, POLITICAL, AND AESTHETIC \\ VALUES IN CHILDHOOD EDUCATION
}

\author{
Ivone Oliveira TAVERNARD ${ }^{1}$, Luzia Batista de Oliveira SILVA ${ }^{2 *}$, JuniorTAVERNARD ${ }^{3}$ \\ ${ }_{1}^{1}$ Doutoranda pela Universidade Federal de São Carlos - UFSCar/SP, São Carlos, SP, Brasil, iolitav@hotmail.com \\ 2 Pós-doutorada em Filosofia pela UnB - Universidade de Borgonha, Dijon/FR. Programa de Pós-Graduação Stricto Sensu em \\ Educação - PPGSSE/USF, Bragança Paulista, SP, Brasil, luzia.silva@usf.edu.br / lubaos@gmail.com \\ ${ }^{3}$ Doutorando em Educação pela Universidade Estadual Paulista "Júlio de Mesquita Filho" - UNESP-Rio Claro, Rio Claro, SP, Brasil, \\ juniorfilosofia@hotmail.com \\ ${ }^{*}$ Autor de correspondência
}

\section{Resumo}

$\mathrm{O}$ artigo tem como objetivo refletir acerca dos escritos jornalísticos, poéticos e educacionais de Cecília Meireles, particularmente, as Crônicas de Educação. A poeta educadora guiada por uma sensibilidade ímpar olhou para a infância, a criança, a família e a escola e teceu considerações e críticas sobre estas várias dimensões da vida, posicionou-se sobre o cenário da educação de maneira arrojada em prol de uma educação ético-política e estética, almejando sensibilizar os órgãos responsáveis pela educação brasileira, defendendo assim, uma educação para as classes populares como saída emancipatória e de transformação das condições sociais, econômicas e políticas do Brasil, na primeira metade do século XX. Investigou-se nesse artigo como as crônicas jornalísticas e os textos poéticos contribuíram para fomentar as relações da criança com a escola e os educadores; sendo a sensibilidade um elemento fundamental nas/das práticas educativas na infância e no processo de sensibilização do imaginário. Optou-se por uma abordagem crítico-educativa sobre a educação da criança e a infância nos textos da escritora Cecília Meireles.

Palavras-chave: Cecília Meireles. Poesia. Educação e Infância.

\begin{abstract}
This article aims to reflect about Cecilia Meireles' poetic and educacional journalistic writings, particularly, writings from Crônicas de Educação (Chronicles of Education). The poet and educator, guided by an unique sensibility, looks at the childhood, the children, the family, and the school, and she makes considerations and criticims about all these dimensions of life, she stands about education scenario in a bold way, in favor of an ethical-political and aesthetic education, craving to sensitize the responsible organs for Brazilian education, defending an education for the lower classes as an emancipatory way out and a trasnformation way of the social, economy and political conditions in Brazil, in the first half of twentieth century. It also aims to discuss investigations problems, such as the journalistic chronicles and the poetic texts and in which way they can contribute for us to think about the children relations with school and teachers. Why the author's sensibility seems to be a fundamental element of educational pratices in the childhood? What kind of educatoin and what pratices of sensitize the imaginary are fundamentals in the childhood? The masters research is methodologically structured in na critical-reflexive approach about the children's educacion and about the childhood in Meireles' texts, relevants to her child poetics, such as her journalistic/educational chronicles, having by it, the central objective of analisys in this article.
\end{abstract}

Keywords: Cecilia Meireles. Poetry. Education. Childhood.

(C)UNIS-MG. All rights reserved.

How to cite this article: 
TAVERNARD, Ivone Oliveira; SOUZA, Luzia Batista de Oliveira; TAVERNARD, Junior. ESCRITOS E OLHARES PLURAIS, VALORES ÉTICOS, POLÍTICOS E ESTÉTICOS NA EDUCAÇÃO DA INFÂNCIA. Interação, Varginha, MG, v. 21, p. $22,2019$. ISSN 1517-848X / ISSN 2446-9874.

Disponível em: http://periodicos.unis.edu.br/index.php/interacao/article/view/197/171. DOI: https://doi.org/10.33836/interacao.v21i1.197 (editoração da revista)

\section{INTRODUÇÃO}

O trabalho, Escrito e Olhares Plurais, Valores Éticos, Políticos e Estéticos na Educação da Infância apresenta os escritos jornalísticos e poéticos de Cecília Meireles, ressaltando-se sua contribuição para os campos da educação na infância, a família e a escola num período em que o cenário sócio-político e educacional passava por mudanças e reformas, considerando-se que "Toda revolução pressupõe uma transformação". (MEIRELES, 2001, p. 46). Todavia, a transformação almejada pela educadora era a transformação das classes populares mediante uma educação centrada numa formação crítica e emancipatória para as classes mais pobres e desafortunadas do Brasil.

Aranha (2006) lembra a falta de inserção das classes populares na educação, considerandose que o ideário da escola laica, gratuita e universal já era apregoado desde o século XVIII sob a responsabilidade do Estado. Haja vista, nesse período a conquista da educação pública, foi um marco nas sociedades liberalistas, e deveria ser uma prioridade para governos democráticos. Já a educação a partir do século XX muito importante para a formação do cidadão: "diante da importância, cada vez maior a educação assumiu caráter político, devido ao seu papel na sociedade como instrumento de transmissão da cultura, ou seja, o sujeito político que conhece seus direitos e deveres" (p. 245). A educação neste contexto de mudanças passou a ser uma esperança para a sociedade, especialmente para as classes populares.

É neste contexto que Cecília Meireles apresenta seu posicionamento político e suas reflexões como poeta e cronista da educação, porque "Nunca se viu, como agora, tão grande movimento, no Brasil, em favor da educação popular". (MEIRELES, 2001, p. 27); a educação deveria ser respeitada em todos os níveis e instâncias governamentais, comenta a escritora.

Sua trajetória formativa e profissional e suas crônicas educativas contribuíram com questões e posicionamentos pedagógicos. Sua visão multifacetada e plural sobre o mundo, permitiu-lhe entender a pluralidade e a diversidade do porquê gostava, generosamente de "gente", e de ser gente, gostava de ser um ser humano; também gostava de discutir e dialogar sobre questões englobando a educação, o ensino e a criança. Temas para a autora, intrinsecamente interligados.

O labor e o clamor poético em suas crônicas de educação são fontes de inspiração, de reflexão sobre a formação humana, porque "se a obra da educação consiste na formação, parece que sua maior dificuldade reside no despertar do indivíduo para o conhecimento ou sentimento dessa necessidade" (MEIRELES, 2001, p.59). Para a sociedade, a escola "representava a esperança de democratização da sociedade" (ARANHA, 2006, p. 245). Assim, o despertar da educação para a formação pressupõe transformação do sujeito, participação política, cultural e entrega de si. 


\section{A ESCRITORA-POETA EDUCADORA}

Aos dezoito anos, Meireles apresentou-se para a sociedade como escritora, com o livro de poesia: Espectros (1919) - retratando poemas simbolistas, nos quais a solidão, o efêmero e o sentimento de espiritualidade são recorrentes. Esse livro de poemas é o seu primogênito dentre as várias obras literárias que configuram sua carreira de escritora, durante 45 anos de dedicação e amor à literatura e ao pensamento crítico.

Em 1924, a escritora publicou a cartilha Criança, meu amor. Livro considerado pela autora uma "obra-prima por expressar uma concepção ética da educação", por compreender que o significado ético e a sensibilização na educação da criança são elementos fundamentais.

A cartilha traz uma imagem poética da infância com conotação moral. Foi composta por quatro mandamentos (cânones) que se constituem como sacerdócios para o recepcionamento e as relações da criança com os colegas e os professores, no aprendizado escolar.

Os quatro mandamentos são: I - Devo amar a escola, como se fosse o meu lar; II - Devo amar e respeitar a professora como se fosse minha mãe; III-Devo fazer dos meus colegas meus irmãos e IV - Devo ser verdadeiro. A obra é radical, profunda e significativa e permanece um desafio para os dias atuais em que a tônica no ter, impõe para a sociedade um consumo operante, que faz parecer substituível a questão ontológica, do ser sujeito escolar, social, cultural e histórico. Destacam-se os seguintes pontos.

O mandamento I - "Devo amar a escola, como se fosse o meu lar", é uma leitura poética e "extremamente positivada" do espaço da educação escolar e da formação sociocultural e histórica das pessoas desde a mais tenra idade. A autora concebe a escola como um segundo lar para a criança, isso significa que a escola deveria ser um lugar sagrado, um lugar de sociabilidades e também de ligação afetiva e humana.

Evidentemente, a autora concebeu também a ideia de uma escola "utópica", impregnada de desejos e sensibilidades que, à primeira vista, parece até uma posição ingênua, se considerarmos o contexto atual da educação, mas ao contrário, sua concepção de escola está impregnada de sentidos afirmativos e morais, fundamentais nas relações humanas, como a busca por uma construção de sociabilidade democrática mediada pelas sensibilidades das práticas educativas. Atualmente parece-nos difícil conhecermos o aluno, bem como a escola em que exercemos nosso trabalho docente, no entanto, este conhecimento deve ser buscado e encorajado por todos que se ocupam em ensinar, trocar e aprender com a criança.

Ao usar a palavra lar e não casa, a autora parece ressignificar o contexto da frase, porque casa no sentido literal é tijolo, argamassa, cimento, pedra, areia, enfim, todos os materiais necessários para uma construção, os quais, no final da obra, formam a imagem de uma casa. Já a palavra Lar se refere ao lugar onde as pessoas habitam, o domicílio de cada um, lugar onde as pessoas dão vida e sentido à existência no convívio com outros seres humanos/familiares.

No segundo mandamento II - "Devo amar e respeitar minha professora como se fosse minha mãe", a escritora ao mesmo tempo em que aponta sua preocupação com a educação da criança, prometeicamente denuncia, mas também assume que a perda das vísceras do educador são partes de um processo educacional permeado de excessos, cobranças, mudanças não compreendidas e transformações vagarosas quando o mundo está em total ebulição. Contudo, acredita que é a dedicação desses pequenos e batalhadores Prometeu-Quíron, os que contribuem para a concretização das tarefas pedagógicas, bem como, o excesso de zelo e dedicação no cumprimento de atividades para com seu papel de educador, ainda que, as consequências sejam a 
privação do descanso salutar e reparador das energias esgotadas, negando também ao próprio corpo o poder de manifestar cansaço, fadiga, decepções, doenças e males que os desgastam, deixando sobressair que a preocupação em zelar pela criança é fundamental e um ato de extrema generosidade, privando-se também de tempo para o entretenimento, o estar com os familiares e amigos, com suas crianças, condenando de certa forma o educador a assumir o papel de anjo familiar e zelador da criança.

Especialmente, porque lhes são sagrados os sentimentos de amor e respeito do professor pela criança e desta para o professor. Amar o professor como se ama a própria mãe? Seria esta imagem uma projeção de sua conduta e atuação pedagógica, marcando os seus sentimentos na relação com as crianças, como educadora e diretora escolar? Seu respeito e sentimento pela criança parece muito acima de qualquer sentimento de medo ou submissão, prevalecendo os sentimentos de generosidade, admiração e afetividade.

O terceiro mandamento III - "Devo fazer dos meus colegas meus irmãos", nos faz refletir sobre a questão do ser e não do ter no sentido ético. Refletir para o que estamos educando e por que educamos desde a mais tenra idade? O que podemos esperar de uma educação dos sentimentos pautando por um imaginário criador, pela curiosidade e razão sensível? O que pode a educação fazer pela criança e com a criança?

A sociabilidade parece a tônica deste mandamento, porque pode estreitar os laços de "civilidade" e cooperação entre as pessoas, entre as crianças e o educador. A diversidade também parece ser a tônica nesta questão da sociabilidade e dos sentimentos de partilha e pertença, quando a autora classifica de maneira ética o que se pode encontrar numa escola ou num espaço de sala de aula: deve-se ou pode-se conhecer aqueles que são desconhecidos e ao mesmo tempo se tornar fraternos.

O que são ricos e pobres numa sala de aula? Alunos "ricos e pobres" podem se encontrar no mesmo espaço de uma sala de aula e serem amigos e ou fraternos? Será que é possível a "educação como um direito"? O que são alunos "adiantados e atrasados" numa mesma sala de aula? Como eles podem se ajudar e se superarem? Os que são os alunos "bons e maus"? Será que compete ao "aluno bom" SER um exemplo para educar o mau aluno? O que são alunos "inteligentes ou não inteligentes"? Existem alunos desprovidos de inteligência? Como respeitar as diferentes inteligências na educação? A autora jamais expressou que algumas crianças podem não ser inteligentes, essa talvez seja a denúncia implícita de como alguns educadores contagiados pelo racionalismo vigente agiam, todavia, o que será que a autora entendia como sendo sinal de inteligência numa criança?

Chama a atenção sua defesa de uma educação ética como forma de fugir dos discursos da escola racionalista, que classificava o discurso sobre a inteligência, desconsiderando que a experiência do ser humano é de grande valia, que o ajuda na construção da sua inteligência e identidade. Afirma ainda os direitos e deveres das crianças, numa concepção cívica e democrática de educação, espera que as crianças possam se ajudar e cooperar, umas com as outras.

A autora tem sonhos e desejos de progresso pessoal e humano, por isso, defende a pedagogia em que o amor e o respeito não são sentimentos piegas, mas estruturantes e constituintes de uma escola que pretende dar continuidade à educação recebida no lar da criança, por isso, a escola deve ser como se fora o seu lar, o segundo lar; respeitar a professora no sentido ético da troca, haja vista, que o aluno deve ser respeitado pelo educador e pela escola, talvez uma espécie de "anjo guardião" da criança no espaço educacional; especialmente aquele que se dedica exaustivamente sobre a criança; que o espaço do educar seja útil e que as crianças se tornem 
adultos prestativos ao outro do contexto social; que a criança aprenda a olhar para o colega como se olharia para um irmão, o que remete aqui ao sentido fraterno, solidário e espiritualizante.

Se a escola proporciona a contemplação, ela também proporciona o exercício de ações generosas, a partilha da vida nas relações de amor e respeito, a riqueza na diversidade étnica, econômica e, fundamentalmente, a compreensão de si no relacionar-se com o outro; a escola é um lugar de pluralidades, um espaço multifacetado, complexo. E como espaço plural, nenhum ser humano pode ser classificado como igual, nem pode ser diminuído pela diferença ou pela diversidade. Na família, a criança aprende a conviver com os irmãos respeitando-os e compartilhando o espaço de convivência, na escola, o aprendizado da convivência não pode ser diferente ou contrapor-se ao cotidiano familiar.

O quarto e último mandamento - "Devo ser verdadeiro", trata da sinceridade do coração, ou seja, do sentimento de honestidade perante o que se sente e o que se diz aos semelhantes.

O mandamento está carregado de valor ético e diz respeito à honestidade e ao caráter, o como encaramos a verdade em nossas vidas. São valores que devem ser aprendidos e cultivados tanto no seio familiar como na escola. Para a educadora poetisa, a escola é - ou deveria ser - um lugar onde devemos ter a coragem de mostrar quem nós somos, se já somos seres mais inteligentes ou ainda não, se somos ricos ou pobres no sentido econômico e espiritual, se somos atrasados ou adiantados, em saberes escolares, se somos sociáveis ou não com as pessoas, se somos praticantes de nossos direitos e deveres, se aprendemos sobre direitos na escola. Esses são os valores aclamados no mandamento III, que a escritora coloca em xeque no que tange a nossa honestidade para assumirmos o que somos capazes de dizer e viver.

Que a escola possa ser também um espaço em que a criança possa expressar-se sem medo, e sem medo especialmente de dizer a verdade, de revelar-se, de ser imatura com relação aos próprios pensamentos. Que o educador possa educar de maneira crítica e aberta a fim de que a criança possa duvidar das suas certezas e incertezas e das verdades confessadas e professadas pelos adultos. Esses mandamentos são determinações éticas a fim de dirigir e direcionar para o bem a "moral", a sabedoria e os sentimentos da criança.

Essa concepção de educação pautada nesses quatros mandamentos seria o contrário do conceito vigente de educação, tradicionalista e opressora, ainda que em certo sentido também o seja. Entretanto, traz consigo a relevância dos valores éticos, essenciais para uma convivência pautada e respaldada na confiança, seja esta na escola, no ambiente familiar ou fora dele, importa-lhe a proteção e o cuidado com e na infância.

Segundo Lobo (2010), Meireles nas décadas de vinte e trinta produziu para o âmbito educacional várias obras didático-pedagógicas, "em 1937, lançou o livro "A festa das letras", primeiro volume da Série Alimentação; em 1939 publicou a obra "Ruth e Alberto resolveram ser turistas", livro adotado pelas escolas públicas para o ensino de ciências sociais no 3o ano elementar. Ruth e Alberto foram adaptados para o ensino da língua portuguesa nos Estados Unidos da América" (LOBO, 2010, p. 15).

A autora incentiva e encoraja uma alfabetização poético-pedagógica com as letras, a fim de ampliar o vocabulário e a formação de palavras em consonância com a linguagem cotidiana da criança; ensina-Ihe a conhecer as letras que compõem as palavras e os seus significados; são ações cotejadas e reveladoras de uma preocupação com a sensibilidade na relação entre educação, conhecimento, percepção e prazer. Compreende-se sua preocupação com a criança e a infância, são 45 anos de trabalho magistral, sobre ética, estética e política, sobre a atuação do educador, sobre os sentimentos da criança na interação com o adulto. 
Seus escritos contribuíram para a discussão sobre a infância e o tratamento dispensado à criança em todas as fases de sua formação escolar, por isso elaborou obras como a cartilha escolar, da qual comentamos anteriormente, e escreveu sobre literatura infantil defendendo uma educação crítica e participativa.

\section{A CRONISTA-JORNALISTA EDUCADORA}

No início da década de 30, Meireles apresentou-se para a sociedade brasileira, especialmente, para a sociedade carioca, como jornalista dos jornais: Página de Educação e Jornal Diário de Notícias, ambos os jornais do Rio de Janeiro.

Valéria Lamego (1996, p. 17) pontua que, "cabia à jovem poeta e educadora levar ao leitor da capital do país suas ideias sobre uma educação livre e moderna, sobre a política nacional e sobre o movimento revolucionário de 1930, que desmoronava diante de seus olhos", contrariando seus sonhos de emancipação e de uma educação política que pudesse alcançar as classes populares a fim de emancipá-las e encorajá-las ao exercício da cidadania.

Para Lamego (1996), a presença da jornalista e cronista da educação dirigindo uma página nos jornais causou rebuliços na capital carioca, projetando-a como uma porta-voz no cenário da educação brasileira, senso por isso, sua carreira como jornalista extensa e potente.

O vasto conhecimento da escritora, jornalista, poeta e pedagoga podem ser comprovados pela ampla produção, escrevendo para o jornal suas crônicas de educação, bem como suas crônicas de viagens e na rádio discutindo temas da cultura geral, sobre ética, estética, arte e educação.

Em seu programa, a escritora lia, comentava e analisava suas próprias crônicas sobre a educação, bem como de outros escritores e pedagogos nacionais e internacionais, cooperando, dessa forma, para a educação das pessoas de todas as classes sociais, considerando-se que um programa de rádio atingia um público bem maior do que aquele público que lia suas crônicas, dado que, o analfabetismo no Brasil era algo problemático, com uma taxa muito elevada.

A educadora, jornalista e cronista deixou-se guiar pela ideia de progresso e educação, por isso, sonhou com um Brasil alfabetizado, com crianças alimentadas e bem tratadas pelos adultos, fora das ruas e inseridas nas salas de aula, com educação para além dos muros escolares, educação como um exercício democrático, uma sociedade que acolhe que educa e se transforma; externou e pediu aos governantes um olhar ético-político e estético sobre a infância e a criança, sobre a educação e a escola. Teceu comentário acerca dos problemas da educação do seu tempo, fez críticas aos espaços educacionais conservadores e sem comprometimento ético-político e estético.

Os princípios e valores éticos defendidos pela autora estavam fundamentados no amor, na solidariedade, na fraternidade, na generosidade, na aceitação da diversidade e no respeito às relações de aprendizado e convivência, na valorização da vida e na dignidade do ser humano. Entendia a autora que era papel da família e também do Estado uma educação capaz de fortalecer a sensibilidade e não negligenciar os aspectos afetivos na aprendizagem e na construção do conhecimento.

As páginas dos jornais para a educadora jornalista e cronista eram suas trincheiras, de onde podia denunciar, dialogar, criticar, ensinar, aprender, trocar, analisar e incentivar ações em prol da educação, tal como, o descaso do Estado para com a educação e a infância desvalida. 
O cenário político em que Meireles atuou como defensora de uma educação ético-política e teceu suas críticas a respeito de uma educação que ela considerava precária no período, era um cenário de Revoluções pelo país, se fazia um clamor em prol dos mais fragilizados (LAMEGO, 1996).

Durante a Revolução de 1930, comandada por Getúlio Vargas, foi criado o Ministério da Educação. Nesse período, o percentual de pessoas alfabetizadas, no país era insignificante. Destarte, os escritos de Meireles logo adquiriram grande significância ao tratarem de temas relevantes para a sociedade, pedia por mudanças e transformações sociais.

A educação criticada por Meireles era a educação tradicional demasiadamente ortodoxa, centrada na figura do professor, com conteúdos voltados para a memorização. E para a autora, a educação era o caminho para a transformação do indivíduo crítico e um caminho para a transformação da realidade brasileira.

\section{A EDUCADORA E A ESCOLA NOVA}

O Movimento Educacional Escola Nova no Brasil foi um movimento pedagógico que já vigorava em países como Estados Unidos, Alemanha e França. Segundo Lamego (1996). O movimento tinha uma proposta de transformação, com novos estudos, como psicologia, sociologia e biologia a fim de compreender o comportamento do ser humano, renovação do papel da escola, do ensino, das disciplinas escolares, da família, da Igreja e do Estado.

Meireles divulgou o Movimento Educacional Escola Nova com a esperança de que este pudesse contribuir para modernizar a educação em solo brasileiro, dado que as indústrias e a burguesia contavam com uma mão de obra mais preparada.

A educadora acreditava que a Escola Nova seria capaz de valorizar a criança na sua integridade, e não dicotomicamente. Uma educação em que o aluno fosse respeitado e os envolvidos nela trabalhassem para sua autonomia, que o educador valorizasse tanto os aspectos culturais e sociais dos indivíduos, como aquilo que estava ligado ao emocional e ao cognitivo deles, por isso, passou a contribuir com o cenário da educação, mediante publicação de escritos jornalísticos com a intenção de ver as transformações na educação acontecerem de fato.

O espaço jornalístico foi sua trincheira para combater as injustiças cometidas pelo governo do presidente Getúlio Vargas e defender-se de seus adversários e dialogar para além da trincheira, com outros educadores.

Ela foi uma escritora eclética, por isso escrevia sobre diferentes gêneros, como: "Arte, ética, nacionalismo, fraternidade, mulher e revolução. A relação entre família, educação e educadores é ressaltada em quase todos os assuntos..." (LAMEGO, 1996 p.33). Um dos objetivos principais de Meireles no jornal era divulgar e difundir a Escola Nova, que tinha como seguidores os professores Fernando de Azevedo e Anísio Teixeira.

No segundo ano dirigindo a Página de Educação Meireles lança seus escritos, na condição de combatente política, aliada ao Movimento Escola Nova, participa do "Manifesto dos pioneiros da Escola Nova" (1932), critica a postura dos governantes, especialmente aqueles que ignoram os problemas da educação.

No terceiro ano no jornal, Meireles continuou empenhada em suas denúncias contra políticos e religiosos, mas procurou inserir em seus escritos também o tema da paz. É o período em que tenta recuperar suas energias para o espaço da educação, busca compreender a educação 
brasileira em franco e profícuo diálogo com educadores de outros países, os quais ela entrevistava.

Dentre os vários gêneros literários em que Meireles escreveu, destacam-se as crônicas sobre educação e infância, família e escola, que a autora publicou nos jornais da época acima mencionados, denunciando a educação oferecida às crianças, questionando a atitude da família e o papel da escola; sempre trazendo à tona a necessidade de uma educação baseada em princípios e valores éticos e estéticos, a valorização da vida e a dignidade do ser humano; sempre externando seus sentimentos para com o campo da educação, o trabalho dos educadores nas escolas.

Para Meireles (2001), o papel da escola como espaço de preparação para a vida tem como tarefa ser um lugar especial e tudo isso parece ser muito pouco. É necessário sonhar mais com a educação.

Cecília Meireles e os intelectuais da época viam na proposta do Movimento Escola Nova, a possibilidade de aproximação entre escola e família. Uma vez que compreendiam que a família se aproximando da escola haveria mais envolvimento com a vida escolar da criança.

A educadora-poeta fazia questão de afirmar que os problemas do país convergiam para um só ponto: tudo era simplesmente uma Questão de educação ${ }^{1}$. Nessa crônica, a autora refere-se à postura de um diretor de uma organização jornalística importantíssima, diretor do Osaka Mainichi e do Tokio Nichi, o qual utilizou esses jornais para mostrar ao mundo a posição dos japoneses em relação à China, referente ao que aconteceu na Manchúria.

Na sua Página de Educação no jornal, Cecília escrevia seus comentários sobre a educação, a fim de informar e mobilizar os professores no sentido de despertá-los a terem uma postura crítica e torná-los conhecedores da real situação da educação e as mudanças que viriam a acontecer, com o Movimento da Escola Nova.

$\mathrm{Na}$ crônica intitulada Educação, acima de tudo², a autora traz ao conhecimento da sociedade brasileira o exemplo dos Estados Unidos que, mesmo passando por crises em sua economia, não permitiram que o ensino público fosse afetado.

Certamente, a autora compreendia que a educação dependia também de uma organização e do interesse por parte dos governantes, destarte, se outros países que investiam na educação popular, o Brasil também poderia fazê-lo. Não de maneira irresponsável, negligente. O país estava passando por uma revolução, esperava-se, portanto, que muito se pudesse conquistar em prol do ensino popular.

Para a educadora cronista e jornalista, era possível uma educação embasada nas tramas da sensibilidade poética, tanto que se utilizou dela para sensibilizar, educar e denunciar, como na crônica Arte e educação ${ }^{3}$

... um instante de beleza pode causar a transformação total de uma vida. Basta que a ação se produza com aquele ritmo e aquela proporção que torna as coisas adequadas e determinam esse ajustamento harmonioso e surpreendente que os homens se acostumam a chamar pelo nome de milagre (MEIRELES, 2001, p. 61).

\footnotetext{
${ }^{1}$ A Crônica, intitulada Questão de Educação, foi escrita no Rio de Janeiro e publicada no Jornal Diário de Notícias, no dia 5 de fevereiro de 1932.

${ }^{2}$ A Crônica, intitulada Educação acima de tudo, foi escrita no Rio de Janeiro e publicada no Jornal Diário de Notícias, no dia 21 de setembro de 1932.

${ }^{3}$ A Crônica, intitulada Arte e Educação, foi escrita no Rio de Janeiro e publicada no Jornal Diário de Notícias, no dia 19 de novembro de 1932.
} 
Na crônica Educação - palavra imensa...4, referindo-se aos problemas da educação brasileira, concluiu que "a educação, nas escolas, propriamente, era a coisa mais fácil de realizar... Facílima... O difícil era obter um ambiente geral favorável à obra..." (MEIRELES, 2001, p. 65), isso porque a criança possuía dois aliados muito fortes, a escola e o lar.

$\mathrm{Na}$ escola, a criança pode contar com a professora para lhe ensinar, guiar, zelar e incentivar o cultivo da sensibilidade no relacionar-se com os outros; depois, ela poderia contar com toda a sua rede parental, que deveria servir de suporte para a educação escolar fornecida pela professora. Mas, algumas vezes a escola que Meireles (2001, p. 166) se referia não era a construída por tijolos ou composta por profissionais, vejamos o que diz a crônica $A$ escola para as crianças! "A escola não é edifício, não é um corpo docente. Escola é um conjunto de crianças"; contudo, também deveria ser lugar de reunião daqueles que se dispõem para a arte complexa de viver, proporcionando condições para o aprender

\section{CONCLUSÃO}

As crônicas de Educação de Cecília Meireles nos ensinam que a formação pedagógica para lidar com a infância e a criança não pode ser desprovida de uma sensibilidade poética, ética e política. Suas crônicas potencializaram a possibilidade de desafiar a sociedade brasileira e seu governo, trabalhando, escrevendo, falando e acima de tudo praticando aquilo que acreditava, porque compreendeu que uma infância protegida iria contribuir para a formação de homens e mulheres mais íntegros e talvez mais autônomos.

Depositou forças que pudessem cooperar para o desenvolvimento da educação urbana e rural, indistintamente. Não limitou suas críticas, fê-las a todos os que descuidavam ou ignoravam a criança empobrecida e a educação popular, por exemplo: aos maus educadores, ao ensino religioso e às instituições mercantilistas, bem como as autoridades políticas.

Incansável em seu ideal de escola igualitária, defensora de todas as crianças, homens e mulheres tivessem seus direitos respeitados e iguais oportunidades de educação. Em certo momento foi silenciada e vencida pelos homens públicos no cenário político, mas não abriu mão de seus ideais. Sua saída da Página de Educação, não cerceou seu punho de continuar sua escrita denunciadora de ações que impediam avanços educacionais. Ao contrário só o fortaleceu para continuar escrevendo e servindo a sociedade com o melhor de si.

Lamego (1996) declarou que Meireles desferiu farpas sem macular a poeta que ela fora, brilhante e exemplar. Como poetisa lírica transvestiu-se da envergadura jornalística, assegurando suas esperanças para construção e transformação social do país com possibilidades de alcançar uma vida mais justa e mais digna para as pessoas; fomentou discussão em torno da infância e fertilizou o jardim de sua vida, fazendo emergir a educadora que militou em favor daqueles que não são ouvidos, que são silenciados e se tornam invisíveis, ainda que bradem, façam ruídos, reclamem e proclamem sua presença em todos os seguimentos de uma sociedade que parece reforçar a invisibilidade de muitos em detrimento da visibilidade de poucos, desconsiderando que e educação é uma mola propulsora e uma saída desse contexto social-político e educacional que se encontra beligerante.

${ }^{4}$ A Crônica, intitulada Educação - Palavra Imensa foi escrita no Rio de Janeiro e publicada no Jornal Diário de Notícias, no dia 67de dezembro de 1932. 
Conclui-se que é possível valorizar a educação da infância se políticas públicas forem cumpridas como consta na LDB 9394/96. E, se os valores éticos se aplicarem efetivamente nas práticas e relações socioeducativas, contribuindo para o desenvolvimento intelectual e humano da criança.

\section{AGRADECIMENTOS}

Agradecemos a Coordenação de Aperfeiçoamento de Pessoal de Nível Superior (CAPES).

\section{REFERÊNCIAS}

ARANHA, Maria Lúcia de Arruda. História da Educação e da Pedagogia. 3. ed, revista e ampliada. São Paulo: Moderna 2006.

LAMEGO; Valéria, A farpa da lira: Cecília Meireles na Revolução de 30. Rio de Janeiro: Record, 1996.

LOBO, Yolanda. Memória e educação: O espírito vitorioso de Cecília Meireles. Revista Brasileira de Estudos Pedagógicos, Brasília, MEC/INEP, n. 187, p. 527, 1996. Coleção Educadores: Cecília Meireles. Fundação Joaquim Nabuco. Recife: Massangana, 2010. 158p.

MEIRELES, Cecília. Criança, meu amor (prosa poética, 1924). 2. ed. Rio de Janeiro: Nova Fronteira, 1977.

MEIRELES, Cecília. Crônicas de Educação (1930-40, 5 vols.) Volume 1 - Rio de Janeiro: Nova Fronteira, 2001. 